\title{
Large apical thrombus due to Takotsubo cardiomyopathy
}

\author{
Geoffrey R Wong, Ross Roberts-Thomson, Saman Laleh Parvar, Adam J Nelson
}

Department of Cardiology, Royal Adelaide Hospital, Adelaide, South Australia, Australia

Correspondence to Dr Geoffrey R Wong, grqwong@gmail.com

Accepted 27 January 2016

\section{DESCRIPTION}

A 55-year-old woman presented with chest pain following a high-speed motor vehicle accident. ECG revealed sinus rhythm with anterior lead ST depression. High-sensitivity troponin increased from baseline 58 to peak of $477 \mathrm{ng} / \mathrm{L}$ (normal $<29 \mathrm{ng} / \mathrm{L}$ ). Transthoracic echocardiogram demonstrated overall mildly impaired left ventricular (LV) function with mid to apical akinesis and preserved basal systolic function typical of Takotsubo cardiomyopathy. There was a large echogenic apical mass suspicious of an apical thrombus (figure 1). Coronary angiography found normal epicardial coronary arteries.

Cardiovascular MRI (CMR) confirmed a large apical thrombus $(20 \times 10 \mathrm{~mm})$ seen on both early and late gadolinium images. There was, however, no myocardial late gadolinium enhancement to indicate myocardial infarction (figure 2). LV findings on CMR were also typical for Takotsubo cardiomyopathy.

The patient was started on therapeutic anticoagulation with warfarin and heart failure therapy with bisoprolol and perindopril. Follow-up imaging after 3 months showed complete resolution of the LV thrombus and recovery in systolic function (figure 2).

Takotsubo cardiomyopathy is increasingly recognised in patients presenting with an acute coronary syndrome. An emotional, psychological or physical stressor is often present. Potential complications include acute pump failure, hypotension, pulmonary oedema and arrhythmia. The prevalence of LV thrombus in Takotsubo cardiomyopathy has been reported in a small case series as being up to $8 \%$ diagnosed on echocardiography. ${ }^{1}$ However, intracardiac thrombus may be under-recognised on echocardiography due to variable image quality, despite ultrasound contrast agents. CMR has been shown to have a superior sensitivity and specificity in the detection of thrombus, particularly on early gadolinium sequences. ${ }^{2}$ Short-term anticoagulation with heparin or warfarin has been successful in resolving intracardiac thrombus, although the

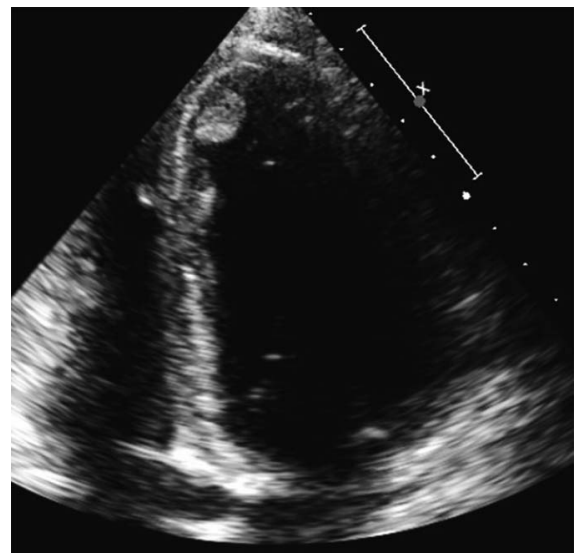

Figure 1 Transthoracic echocardiogram—apical four-chamber view (zoomed). Large echogenic apical mass suspicious for left ventricular thrombus.

duration of therapy is uncertain, and serial imaging is required to assess for thrombus resolution. ${ }^{3}$ At present, there is insufficient evidence to recommend the use of direct oral anticoagulants in this setting and there are no firm clinical guideline recommendations on anticoagulant therapy for the management of LV thrombus in Takotsubo cardiomyopathy. Prophylactic anticoagulation has been suggested, in a small systematic review, for female patients above 65 years of age and those at higher risk of thrombus formation with a large region of akinesis and elevated $\mathrm{C}$ reactive protein. ${ }^{3}$ These patients may benefit from more vigorous higher resolution imaging to assess for $\mathrm{LV}$ thrombus.

Contributors GRW and AJN were responsible for study concept and design. All the authors were responsible for analysis and interpretation of the data. GRW, SLP and RR-T contributed to drafting of the manuscript. GRW and AJN contributed to critical revision.

Competing interests None declared.

Patient consent Obtained.

Provenance and peer review Not commissioned; externally peer reviewed. 


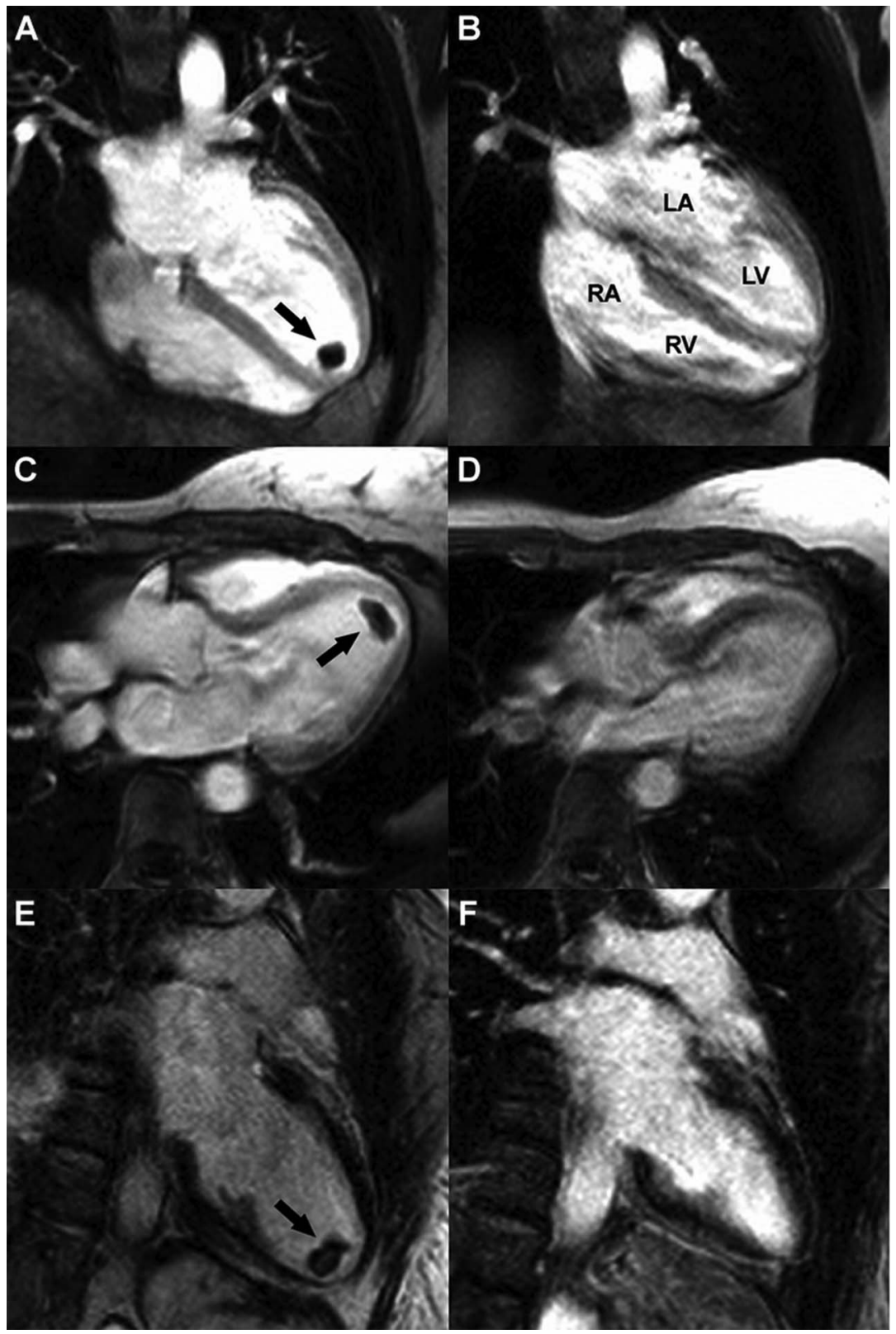

Figure 2 Cardiac MRI. Early gadolinium sequence four-chamber (horizontal long axis) view with large apical thrombus ((A) black arrow) and full resolution on repeat imaging 3 months later (B). Early gadolinium sequence left ventricular outflow tract view with large apical thrombus ((C) black arrow) and resolution on repeat imaging (D). Late gadolinium sequence two-chamber (vertical long axis) view with large apical thrombus ((E) black arrow) and resolution (F). LA, left atrium; LV, left ventricle; RA, right atrium; RV, right ventricle.

\section{Learning points}

- Left ventricular thrombus should be considered in patients with Takotsubo cardiomyopathy, particularly in patients at higher risk of thrombus formation with severe apical dilation and regional wall motion abnormalities.

- Cardiac MRI with gadolinium contrast is a useful adjunct to echocardiography in the diagnosis of left ventricular thrombus.

- Anticoagulation with warfarin or heparin is effective in treating intracardiac thrombus due to Takotsubo cardiomyopathy and should be continued until thrombus resolution. However, the duration of therapy and role, if any, for direct-acting oral anticoagulants remains unclear.

\section{REFERENCES}

1 Haghi D, Papavassiliu T, Heggemann F, et al. Incidence and clinical significance of left ventricular thrombus in Takotsubo cardiomyopathy assessed with echocardiography. OJM 2008:101:381-6.

2 Weinsaft JW, Kim HW, Shah DJ, et al. Detection of left ventricular thrombus by delayed-enhancement cardiovascular magnetic resonance prevalence and markers in patients with systolic dysfunction. J Am Coll Cardiol 2008;52:148-57.

3 de Gregorio C. Cardioembolic outcomes in stress-related cardiomyopathy complicated by ventricular thrombus: a systematic review of 26 clinical studies. Int J Cardiol 2010;141:11-17 
Copyright 2016 BMJ Publishing Group. All rights reserved. For permission to reuse any of this content visit http://group.bmj.com/group/rights-licensing/permissions.

BMJ Case Report Fellows may re-use this article for personal use and teaching without any further permission.

Become a Fellow of BMJ Case Reports today and you can:

- Submit as many cases as you like

- Enjoy fast sympathetic peer review and rapid publication of accepted articles

- Access all the published articles

- Re-use any of the published material for personal use and teaching without further permission

For information on Institutional Fellowships contact consortiasales@bmjgroup.com

Visit casereports.bmj.com for more articles like this and to become a Fellow 